\title{
How long should we talk to patients? A study in doctor-patient communication
}

\author{
V. WRIGHT, R. HOPKINS, ANDK. BURTON \\ From the Rheumatism Research Unit, University Department of Medicine, General Infirmary at Leeds
}

SUMMARY The 13 questions to which 173 rheumatic outpatients most frequently wished to know the answer were made the basis of a structured interview. Two lengths of interview were conducted in a controlled trial (short being of 2 minutes' duration, long ranging from 4 to 11 minutes). Sixty patients referred directly from their general practitioners, and not being in any of the remedial professions, were randomly assigned to one of the 2 groups. They were tested by an independent observer immediately after interview, and one month later at their return appointment, by means of a questionnaire that covered the 13 items of information given to all the patients. The longer interview resulted in significantly more information being retained. Of individual questions only 3 scored significantly better with the longer interview-that about the reasons for $x$-rays immediately after interview, and the role of heredity and the place of rest at delayed recall.

In an era of high-technology medicine communication with the patient remains of the highest importance. A group of patients undergoing abdominal surgery were given details of the type of surgery and the pain they might suffer subsequently. Compared with a group given no information they required less morphine and half as much sedatives in the first 5 days after the operation, and were in hospital 3 days less. ${ }^{1}$ Doctor-patient communication is particularly valuable when dealing with patients who have diseases for which there is no cure, which are chronic in their course, and which may cripple the patient. ${ }^{23}$ Written communications may reinforce the explanation and instructions given by the doctor, and we have investigated the value of booklets and leaflets for rheumatic patients. ${ }^{4-7}$ The first communication, however, will be verbal, and many patients are far from satisfied with what they are told in hospital. ${ }^{8} \mathrm{~A}$ general practitioner in our research group has suggested that a short explanation is as useful as a long one for informing patients. Prolonged interviews are likely to confuse the patient and be counterproductive. This has profound implications in the running of a clinic. The present study ascertained what patients in a rheumatic clinic wanted to know, and whether they retained more after a long or a short interview.

Accepted for publication 12 May 1981.

Correspondence to Professor V. Wright, Rheumatism Research Unit, School of Medicine, 36 Clarendon Road, Leeds LS2 9PJ.

\section{Materials and methods}

173 consecutive patients attending the Rheumatic Outpatient Clinic at the Leeds General Infirmary for the first time were asked what they wanted to know from the doctor. The 13 most frequent requests were used to construct a standard interview. The next 60 patients were then randomly divided into a 'short interview' and 'long interview' group. Patients excluded were those that had been referred from another consultant, those who had previously seen another rheumatologist or an orthopaedic surgeon for their complaint, those under the age of 18 years, and those with some detailed medical knowledge (doctors, nurses, remedial therapists).

Those in the short interview group were given the information about their condition briefly in the structured interview. No opportunity was given for questions. The long interview group had a fuller explanation of the points in the structured interview. Where appropriate, diagrams were drawn to facilitate description. The patients were given the opportunity to ask as many questions as they wished. Both interviews were timed by an independent observer with a stop watch. Immediately afterwards a questionnaire was given by this observer in another room on the points covered in the interview. The answers were marked later as 'true', 'false', or 'not clear'. On review one month later the patients were invited to complete the questionnaire again before seeing the 
Table 1 Details of patients in the 2 interview groups

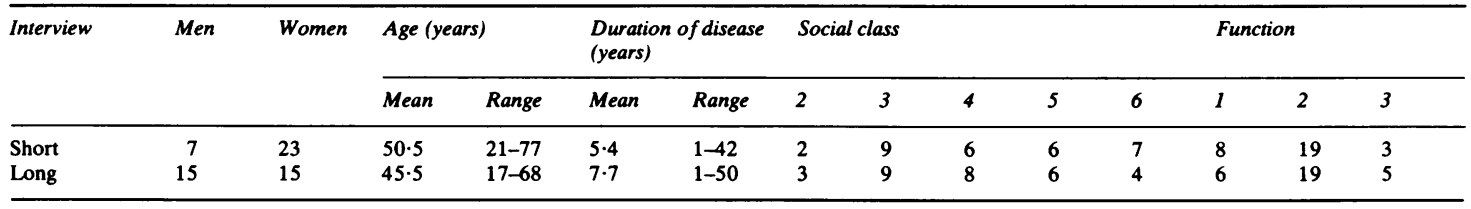

Table 2 Diagnosis of disease

\begin{tabular}{lcc}
\hline Diagnosis & Short & Long \\
\hline Rheumatoid arthritis & 2 & 5 \\
Osteoarthrosis & 11 & 8 \\
Lumbar disc degeneration & 3 & 3 \\
Muscular & 4 & 4 \\
Gout & 1 & 3 \\
Seronegative polyarthritis & 3 & 2 \\
Ankylosing spondylitis & 1 & 1 \\
Paget's disease & 1 & - \\
Chondromalacia patellae & 1 & - \\
Monarticular arthritis & 2 & - \\
Bicipital tendinitis & 1 & - \\
Hypermobility syndrome & - & 1 \\
Polymyalgia rheumatica & - & 1 \\
Plantar fasciitis & - & 1 \\
Raynaud's disease & - & 1 \\
Total & 30 & 30 \\
\hline
\end{tabular}

doctor (they were unaware that it was to be administered).

Other information obtained included the patient's sex, age, occupation, occupation of spouse, social class, diagnosis, duration of illness, functional grade (from 1 = normal to 5 = bed-ridden), and academic qualifications.

\section{Results}

IN ITIAL S URVEY

The questions to which patients most frequently wished to know the answers were: the diagnosis, the cause, heritability, outlook, what should be done positively, how much exercise should be taken, the place of rest, what should be avoided, diet, medication, frequency of dosage, reasons for blood tests, and reasons for $x$-rays. Other questions asked less frequently were not detailed in the structured interview. They included the influence of the weather, 'Should I emigrate?' 'Why do my doctor's tablets upset me?' 'Could I go privately?' and 'What will electric treatment do?' $11 \%$ did not wish to know anything.

\section{DESCRIPTION OF PATIENTS}

Table 1 gives details of the patients in the 2 groups. More women were interviewed briefly, but analysis showed no difference in the scores between the sexes, as others have found. ${ }^{9}$ The slightly older age of the short interview group was largely accounted for by 3 patients over the age of 70 years (none over 77 years). In the short interview group 5 patients had the general certificate of education (CSE) or O levels; 3 of them had A levels. In the long interview group 7 had CSE or O levels; 3 of them had A levels and 2 had a degree. The diagnoses are shown in Table 2.

\section{IN FORMATION RETAINED}

The short interview never occupied more than 2 minutes. The long interview averaged 7 minutes, ranging from 4 to 11 minutes. Immediately after the interview and one month later significantly more

Table 3 The correctness of answers in the 2 lengths of structured interview immediately after and one month later

\begin{tabular}{|c|c|c|c|c|c|c|c|c|c|c|c|c|}
\hline & \multicolumn{6}{|c|}{ Immediate recall } & \multicolumn{6}{|c|}{ Delayed recall } \\
\hline & \multicolumn{3}{|c|}{ Short Interview } & \multicolumn{3}{|c|}{ Long interview } & \multicolumn{3}{|c|}{ Short interview } & \multicolumn{3}{|c|}{ Long interview } \\
\hline & $T$ & $\boldsymbol{F}$ & $N C$ & $T$ & $\boldsymbol{F}$ & $N C$ & $T$ & $F$ & $N C$ & $T$ & $F$ & $N C$ \\
\hline 1. Diagnosis & 14 & 3 & 13 & 14 & - & 16 & 16 & 4 & 10 & 20 & - & 10 \\
\hline 2. Cause & 15 & 4 & 11 & 13 & 1 & 16 & 10 & 7 & 13 & 13 & 1 & 16 \\
\hline 3. Inheritance & 18 & 8 & 4 & 21 & 6 & 3 & 15 & 12 & 3 & 23 & 4 & 3 \\
\hline 4. Outlook & 20 & 3 & 7 & 27 & - & 3 & 18 & 4 & 8 & 21 & 1 & 8 \\
\hline 5. Do positively & 19 & 1 & 10 & 26 & - & 4 & 19 & 1 & 10 & 16 & 4 & 10 \\
\hline 6. Exercise & 17 & 1 & 12 & 23 & - & 7 & 16 & 3 & 11 & 22 & 2 & 6 \\
\hline 7. Rest & 19 & 1 & 10 & 22 & 1 & 7 & 12 & 5 & 13 & 18 & 1 & 11 \\
\hline 8. Avoid & 23 & 1 & 6 & 24 & 1 & 5 & 23 & 3 & 4 & 18 & 3 & 9 \\
\hline 9. Diet & 21 & 2 & 7 & 26 & 1 & 3 & 20 & 3 & 7 & 23 & 3 & 4 \\
\hline 10. Medication & 15 & 1 & 14 & 19 & - & 11 & 20 & - & 10 & 20 & - & 10 \\
\hline 11. Frequency of medication & 25 & 1 & 7 & 24 & 1 & 5 & 25 & - & 5 & 29 & - & 1 \\
\hline 12. Why blood tests? & 6 & 1 & 23 & 13 & - & 17 & 6 & - & 24 & 10 & 2 & 18 \\
\hline 13 . Why $x$-rays? & 8 & - & 22 & 18 & - & 12 & 11 & - & 19 & 16 & - & 14 \\
\hline
\end{tabular}

$T=$ true; $F=$ false; $N C=$ not clear 
information was recalled by those who had been interviewed at more length $\left(\chi^{2}=17 \cdot 26, \mathrm{p}<0.001 ; \chi^{2}\right.$ $=10 \cdot 16, p<0 \cdot 01$ respectively). When 2 marks were assigned for a correct answer, -1 for not clear, and -2 for false, the mean scores were: immediately after the short interview 18.5 and after the long interview $31 \cdot 5$; one month after the short interview $15 \cdot 1$ and after the long interview $25 \cdot 1$. For only 3 individual questions were there statistically significant differences in the answers (Table 3 ). Immediately after the interview those with the long interview scored more on the reasons for $x$-rays $\left(x^{2}=6.78, p<0.01\right)$, but there was no significant difference one month later. At delayed recall significant differences occurred on the role of heredity $\left(\chi^{2}=5 \cdot 68, \mathrm{p}<0.01\right)$ and the place of rest $\left(\chi^{2}=4 \cdot 02, p<0.01\right)$.

\section{Discussion}

In an industry which is consumer-orientated it is important to find what the consumer wants to know. McGhee $^{10}$ found that $65 \%$ of patients were dissatisfied with the amount of information they were given in hospital. Our preliminary study defined those questions most frequently asked in a rheumatic clinic. A more sophisticated group of patients, or those with severer disease, might well ask other questions. Some of these are discussed in a recent book on nursing. ${ }^{11}$ Those from another culture, such as North America, may be more exacting in the time they wish to spend discussing their condition with the doctor. It should be noted that not all patients wished to know anything ( $11 \%$ of our preliminary survey had no questions to ask the doctor). In a previous study of hip arthroplasty we found that some patients, even when given the chance to ask questions, replied, 'I don't want to know anything - as long as he doesn't cut me open, that is all that matters.' Their definition of being cut open was an abdominal operation. The fact that a surgeon put a great gash down their thigh and brutally dislocated their hip was of little moment provided their vitals were not exposed.

Nevertheless many patients do want to know about their illness. Moreover they usually want to know from the doctor. In a recent study on a surgical ward $45 \%$ of patients wanted information from the man who did the operation, $27 \%$ from the doctor with first-hand information, $17 \%$ from the consultant, $6 \%$ from the sister, $4 \%$ from the nurse, and $10 \%$ had no preference. ${ }^{12}$ This observation is interesting in view of the present emphasis on nurse counselling. In a busy outpatient clinic (our clinic has 8517 patientvisits annually) time is at a premium. Given that it is imperative we explain to the patient, the length of the interview becomes important. These findings suggest that it is worth explaining to patients at some length if we wish to impart information to them both on a short and on a long term basis. Interestingly, several patients given the 2-minute explanation commented spontaneously to the assessor, 'Wasn't it kind of the doctor to go into such detail with me.' This may be a reflection on their usual reception at the hands of doctors, and it shows the value of a structured interview in which the patient is informed of salient facts. The patients who said this scored no better than the others, but at least they felt better and that is good therapy. This has modified our practice in that we use the structured interview under all circumstances. Among other things it ensures that you always have a starting point in talking to the patient.

\section{References}

1 Egbert L D, Battit G E, Welch C E, Bartlett M K. Reduction of post-operative pain by encouragement and instruction of patients. A study of doctor-patient rapport. New Engl J Med 1964; 270: 825-7.

2 Ley P, Spelman M S. Communication in an out-patient setting. $\mathrm{Br}$ J Soc Clin Psychol 1965; 4: 114-6.

3 Joyce C R B, Caple G, Mason M, Reynolds E, Mathews J A. Quantitative study of doctor-patient communications. $Q J$ Med 1969; 38: 183-94.

4 Moll J M H, Wright V. Evaluation of the Arthritis and Rheumatism Council Handbook on Gout: An objective study of doctor-patient communication. Ann Rheum Dis 1972; 31: 405-11.

s Moll J M H, Wright V, Jeffrey M R, Goode J D, Humberstone $P$ M. The cartoon in doctor-patient communication. Further study of the Athritis and Rheumatism Council Handbook on Gout. Ann Rheum Dis 1977; 36: 225-31.

- Wright V, Hopkins R. Communicating with the rheumatic patient. Rheumatol Rehabil 1977; 16: 107-18.

7 Wright V, Hopkins R, Jackson M. Instructing patients in physiotherapy - an example using three methods. Rheumatol Rehabil 1980; 19: 91-4.

'Reynolds M. No news is bad news-patients' views about communication in hospital. Br Med J 1978; i: 1673-6.

- Anderson J L, Dodman S, Kopelman M, Fleming A. Patient information recall in a rheumatology clinic. Rheumatol Rehabil 1979; 18: 18-22.

10 McGhee A. The Patient's Attitude to Nursing Care. Edinburgh: Livingstone, 1961.

1 Swinson D R, Swinburn W R. Rheumatology. London: Hodder and Stoughton, 1980.

12 French K. Some anxieties of elective surgery patients and the design for reassurance and information. Res Psychol Med 1979; 2: 336-43. 